\title{
Prandial subcutaneous injections of glucagon-like peptide-1 cause weight loss in obese human subjects
}

\author{
Erik Näslund ${ }^{1 \star}$, N. King ${ }^{2}$, S. Mansten ${ }^{3}$, N. Adner ${ }^{3}$, J. J. Holst ${ }^{4}$, M. Gutniak ${ }^{3}$ and P. M. Hellström ${ }^{5}$ \\ ${ }^{1}$ Division of Surgery, Karolinska Institutet Danderyd Hospital, SE-182 88 Danderyd, Sweden \\ ${ }^{2}$ Department of Biopsychology, University of Leeds, Leeds, UK \\ ${ }^{3}$ Division of Medicine, Karolinska Institutet South Hospital, Stockholm, Sweden \\ ${ }^{4}$ Department of Medical Physiology, University of Copenhagen, Copenhagen, Denmark \\ ${ }^{5}$ Department of Gastroenterology and Hepatology, Karolinska Hospital, Karolinska Institutet, Stockholm, Sweden
}

(Received 21 June 2003 - Revised 14 October 2003 - Accepted 6 November 2003)

\begin{abstract}
Recombinant glucagon-like peptide-1 (7-36)amide (rGLP-1) was recently shown to cause significant weight loss in type 2 diabetics when administered for 6 weeks as a continuous subcutaneous infusion. The mechanisms responsible for the weight loss are not clarified. In the present study, rGLP-1 was given for $5 \mathrm{~d}$ by prandial subcutaneous injections (PSI) ( $76 \mathrm{nmol} 30 \mathrm{~min}$ before meals, four times daily; a total of $302.4 \mathrm{nmol} / 24 \mathrm{~h}$ ) or by continuous subcutaneous infusion (CSI) $(12.7 \mathrm{nmol} / \mathrm{h}$; a total of $304.8 \mathrm{nmol} / 24 \mathrm{~h})$. This was performed in nineteen healthy obese subjects (mean age 44.2 (SEM 2.5) years; BMI $39.0($ SEM 1.2) kg/m²) in a prospective randomised, double-blind, placebocontrolled, cross-over study. Compared with the placebo, rGLP-1 administered as PSI and by CSI generated a $15 \%$ reduction in mean food intake per meal $(P=0.02)$ after $5 \mathrm{~d}$ treatment. A weight loss of $0.55($ SEM 0.2$) \mathrm{kg}(P<0.05)$ was registered after $5 \mathrm{~d}$ with PSI of rGLP-1. Gastric emptying rate was reduced during both PSI $(P<0.001)$ and CSI $(P<0.05)$ treatment, but more rapidly and to a greater extent with PSI of rGLP-1. To conclude, a $5 \mathrm{~d}$ treatment of rGLP-1 at high doses by PSI, but not CSI, promptly slowed gastric emptying as a probable mechanism of action of increased satiety, decreased hunger and, hence, reduced food intake with an ensuing weight loss.
\end{abstract}

Glucagon-like peptide-1: Obesity: Gastric emptying: Weight loss

Glucagon-like peptide-1 (GLP-1 (7-36)amide) exerts an antidiabetogenic effect in man by stimulating insulin release, lowering glucagon secretion, inhibiting gastric emptying and probably also by enhancing glucose utilisation (Gutniak et al. 1992; Nauck et al. 1993b). The peptide is considered as an important incretin (Kreymann et al. 1987; Nauck et al. 1993a). In recently published studies GLP-1 improved glycaemia in diabetic patients of both type 1 and type 2 . These properties of the peptide make GLP-1 a potential drug in the treatment of diabetes mellitus, especially type 2 (Gutniak et al. 1992; Nauck et al. 1993 b)

Since GLP-1 immunoreactive nerve fibres have been found in areas of the brain that receive afferents from the gastrointestinal tract and control food intake (Kreymann et al. 1989; Larsen et al. 1997), and the peptide is a potent inhibitor of gastric emptying (Näslund et al. $1999 \mathrm{~b})$, it is expected to influence eating behaviour. Indeed, GLP-1 has been shown to be a potent inhibitor of food intake in both animals and human subjects. In animals, the central administration of GLP-1 inhibits food intake and the administration of the GLP-1 receptor antagonist exendin (9-39) increases food intake (Turton et al. 1996). In human subjects, intravenous administration of GLP-1 has been shown to decrease food intake and hunger feelings in normal-weight subjects (Flint et al. 1998; Gutzwiller et al. 1999b), obese subjects (Näslund et al. 1998, 1999a), and patients with non-insulin-dependent diabetes mellitus (Gutzwiller et al. 1999a). In a recent meta-analysis with data from 115 subjects, energy intake was decreased by $11.7 \%$ during GLP-1 infusion (Verdich et al. 2001). In a study in patients with non-insulin-dependent diabetes mellitus, appetite was reduced during $48 \mathrm{~h}$ of continuous infusion of GLP-1 (Toft-Nielsen et al. 1999) and recent data suggest that 6 weeks of subcutaneous (SC) infusion of GLP-1 reduces body weight in patients with non-insulin-dependent diabetes mellitus (Zander et al. 2002). No studies of the long-term effects of GLP-1 on food intake and body weight have been performed in obese, but otherwise healthy, subjects.

One factor limiting the therapeutic potential of GLP-1 is its short half-life. Our group has reported a very rapid

Abbreviations: CSI, continuous subcutaneous infusion; GLP-1, glucagon-like peptide-1; ITT, intention to treat; PSI, prandial subcutaneous injections; rGLP-1, recombinant glucagon-like peptide-1; SC, subcutaneous; T50, gastric half-emptying time; VAS, visual analogue scale; VIKTORIA, universal eating monitor.

* Corresponding author: Dr Erik Näslund, fax +46 865577 66, email Erik.Naslund@kir.ds.sll.se 
absorption of the peptide from SC tissue (Gutniak et al. 1994). Since intravenous studies have shown that continuous delivery of GLP-1 affects satiety and the greatest effect was observed $3-4 \mathrm{~h}$ after a meal, it is plausible that an injection in connection with a meal could have a similar effect to a continuous infusion.

The objectives of the present study were: first, to determine if $5 \mathrm{~d}$ of recombinant GLP-1 (7-36)amide (rGLP-1) administration influences eating behaviour and food intake in obese healthy volunteers as studied with prandial SC injections (PSI) and continuous SC infusion (CSI); second, to investigate the effect of these treatments on body weight; third, to determine the effect of the two treatment regimens on gastric emptying as studied using the paracetamol (acetaminophen)-absorption technique (Näslund et al. 2000).

\section{Material and methods}

\section{Subjects}

The inclusion criteria were healthy men or post-menopausal women (as men and post-menopausal women have been shown to have similar rates of gastric emptying; Grybäck et al. 2000) between 18 and 65 years of age. The subjects should consume at least four solid meals/d and demonstrate a stable weight not varying more than $\pm 5 \%$ during the last month. Nineteen subjects (seventeen men, BMI $40 \cdot 0 \pm 1 \cdot 3 \mathrm{~kg} / \mathrm{m}^{2}$, age $43.4 \pm 3.0$ years) were recruited for the study. Of these, fifteen (thirteen men, BMI $39.4 \pm 1 \cdot 3 \mathrm{~kg} / \mathrm{m}^{2}$, age $43 \cdot 0 \pm 3 \cdot 0$ years) completed all four $5 \mathrm{~d}$ treatments. The two women were 51 and 55 years old with BMI of 38 and $36 \mathrm{~kg} / \mathrm{m}^{2}$, respectively.

\section{Study protocol}

The study was performed according to good clinical practice guidelines and was approved by the Karolinska Institutet regional ethics committee. The study design was a randomised cross-over, double-blind, placebo-controlled study where subjects received either rGLP-1 or saline CSI or rGLP-1 or saline PSI for five continuous days.
In this way, each subject was examined on four occasions with $9 \mathrm{~d}$ separating each treatment period (Fig. 1).

\section{Dose selection and drug administration}

The dose of rGLP-1 was chosen to ensure therapeutic levels of the peptide. In previous studies (Gutniak et al. 1992; Flint et al. 1998; Gutzwiller et al. 1999b), GLP-1 has been given as intravenous infusions ranging from 45 to $75 \mathrm{pmol} / \mathrm{kg}$ per $\mathrm{h}$ in order to achieve plasma levels ranging between 60 and $200 \mathrm{pmol} / \mathrm{l}$. In other studies where the peptide was given as SC injections (Gutniak et al. 1994; Nauck et al. 1996; Todd et al. 1997) of 0.4 to $1.5 \mathrm{nmol} / \mathrm{kg}$, peak levels of GLP-1 ranging between 100 and $550 \mathrm{pmol} / 1$ were obtained. According to clinical experience and a dose-response study of Ritzel et al. (1995), plasma levels above $150 \mathrm{pmol} / \mathrm{l}$ should be avoided because of possible side effects; mainly vomiting and dizziness. In the present study, the doses of $120 \mathrm{pmol} / \mathrm{kg}$ per $\mathrm{h}$ for the SC infusion and $0.8 \mathrm{nmol} / \mathrm{kg}$ for the SC injection would be expected to raise plasma GLP-1 concentrations to $100-200 \mathrm{pmol} / \mathrm{l}$, which is the optimal therapeutic range according to up-to-date clinical experience. rGLP-1 (BioNebraska Inc., Lincoln, NB, USA) was administered as a CSI at a dose of $120 \mathrm{pmol} / \mathrm{kg}$ per min with a MiniMed pump (MiniMed Inc., Northridge, CA, USA) or as PSI at $0.8 \mathrm{nmol} / \mathrm{kg}$ given $30 \mathrm{~min}$ before four main meals/d. As a control, normal saline (Natriumklorid Pharmacia $9 \mathrm{mg} / \mathrm{ml}$; Pharmacia \& Upjohn, Stockholm, Sweden) was used. Based on our previous studies (Näslund et al. 1999a), with intravenously administered GLP-1, a power analysis was performed, where with a power of $80 \%$ we expected to be able to detect a $870 \mathrm{~kJ}$ change in food intake and $6.5 \mathrm{~mm}$ change in hunger visual analogue scale (VAS) rating between the placebo and GLP-1.

\section{Study visits}

Screening visit. The subjects were informed regarding the study protocol and screening regarding the inclusion and
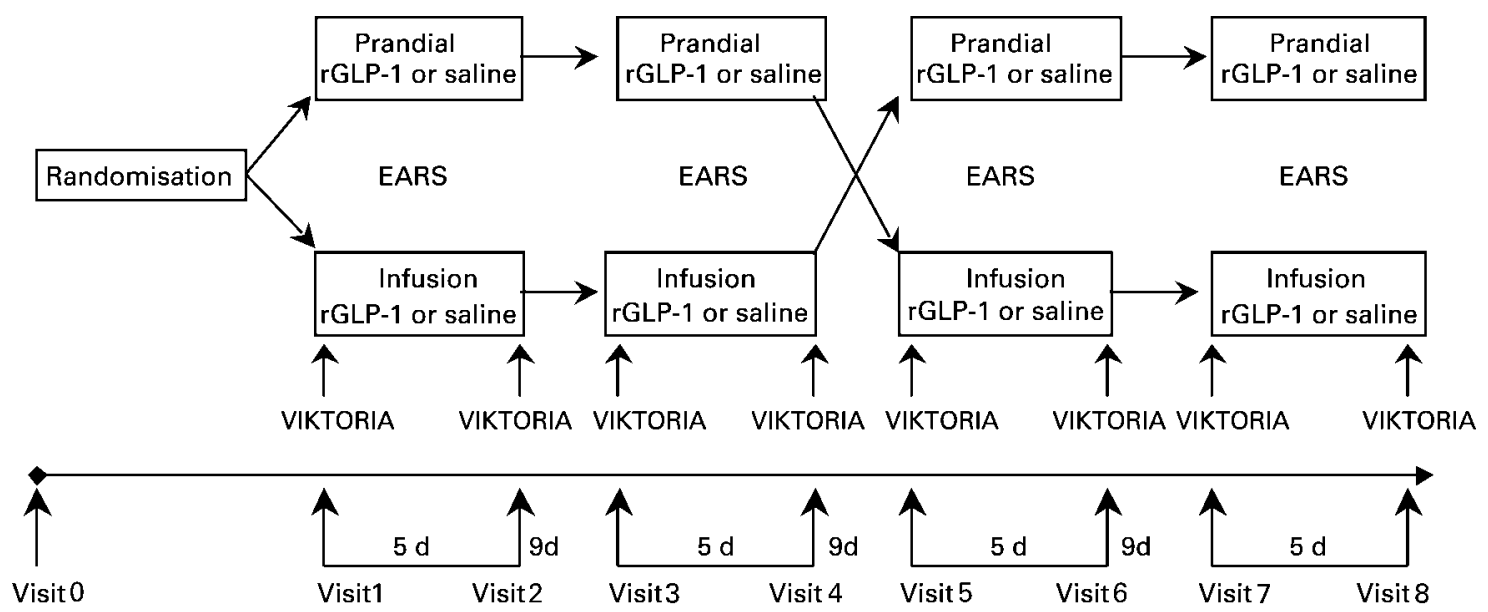

Fig. 1. Schematic presentation of the randomised cross-over, double-blind, prospective placebo-controlled study design where subjects received either recombinant glucagon-like peptide-1 (rGLP-1) or saline as a continuous subcutaneous infusion or rGLP-1 or saline as prandial subcutaneous injections for $5 \mathrm{~d}$ in a row, with a wash-out period of $9 \mathrm{~d}$ in between. EARS, electronic visual analogue scales; VIKTORIA, universal eating monitor. 
exclusion criteria. Baseline anthropometric data were obtained, as was baseline blood chemistry.

Visit 1. After a $9 \mathrm{~h}$ fast, refraining from alcohol and exercise for $24 \mathrm{~h}$, the subjects came to the clinic at 07.15 hours. Baseline data were obtained and the subjects were instructed regarding the SC infusion and prandial injections. At $30 \mathrm{~min}$ before an energy-fixed breakfast of $2.4 \mathrm{MJ}$ (16\% energy as protein, $36 \%$ energy as carbohydrate and $48 \%$ energy as fat), either the CSI or PSI was begun.

A test meal was served on a universal eating monitor (VIKTORIA) at 12.00 hours. The VIKTORIA has been described in detail elsewhere (Barkeling et al. 1990). In short, the VIKTORIA consists of a plate, with a homogeneous meal in abundance, which is placed on a scale connected to a computer. The total food intake, meal duration and eating rate are measured by the VIKTORIA. The test meal was an industrially produced Swedish hash with a standard energy content of $0.7 \mathrm{MJ}(170 \mathrm{kcal}) / 100 \mathrm{~g}$ consisting of diced meat, onions and potatoes, mixed and fried (Oxpytt; Nestlé AB, Bjuv, Sweden). The energy percentages were: protein, 16; carbohydrate, 36; fat, 48. The subjects were instructed to eat freely until completely full and satisfied. One glass $(200 \mathrm{ml})$ of plain water and one glass with the dissolved paracetamol (see later) were given with the meal.

Feelings of hunger, satiety, thirst and nausea were assessed by the use of VAS 15 min before, 60, 120, 180, and $300 \mathrm{~min}$ after food intake on a hand-held computer (Psion 3Mx; Psion plc, London, UK) using EARS software (BioPsychology Group, School of Psychology, University of Leeds, Leeds, UK) for electronic recording. The same recording equipment was used for ambulatory recordings of hunger, satiety, thirst and nausea at home; before and after meals on days 2, 3 and 4 in-between the study meals on days 1 and 5 .

Gastric emptying rate was assessed by utilising paracetamol absorption from the intestine after oral ingestion as a marker (Näslund et al. 2000). Plasma concentrations of paracetamol were measured at $0,15,30,60,90,120$ and $180 \mathrm{~min}$ after the ingestion of $2 \mathrm{~g}$ paracetamol with the test meal. Plasma samples were stored at $-20^{\circ} \mathrm{C}$ until the analysis of paracetamol by fluorescence-immunoassay (IMX; Abbott Laboratories, Chicago, IL, USA). The assay had a CV of $5 \%$. The gastric-emptying profile was estimated after the conversion of paracetamol plasma concentration values to accumulated values, i.e. total absorption of the drug. In this way a gastric-emptying curve from 100 to $0 \%$ adapted to a third-degree polynomial was obtained for each subject. The gastric half-emptying time (T50) was defined as the period from the end of food intake with paracetamol until $50 \%$ of gastric emptying was achieved (Näslund et al. 2000). The obtained values for paracetamol absorption during treatment with rGLP-1 were expressed in relation to paracetamol absorption during treatment with saline.

Blood samples were also obtained for the analysis of plasma concentrations of glucose, glucagon, insulin and GLP-1; 15 min before food intake, at the start of food intake and at 15, 30, 60, 90, 120, 150, 180, 240, and $300 \mathrm{~min}$ after food intake. Blood samples were collected in EDTA tubes placed on ice. The samples were centrifuged at $4^{\circ} \mathrm{C}$ for $10 \mathrm{~min}$ at $3000 \mathrm{rpm}$. Plasma was collected and stored at $-20^{\circ} \mathrm{C}$ for analysis in one series.

Glucagon was assessed with an assay directed against the C-terminus of the glucagon molecule (antibody no. 4305 ) and therefore measures glucagon of mainly pancreatic origin. The detection limit of the assay is $1 \mathrm{pmol} / \mathrm{l}$, with a $\mathrm{CV}$ of $5 \%$.

Insulin was analysed using a sandwich enzyme immunoassay (Insulin Kit K6219; DACO, Copenhagen, Denmark). The assay cross-reacts to $0.3 \%$ with pro-insulin but not with $\mathrm{C}$-peptide. The detection limit of the assay is $3 \mathrm{mU} / \mathrm{l}$ and the $\mathrm{CV}$ is $8 \%$.

Glucose was analysed using an enzyme assay (mutarotase and glucose dehydrogenase) with reagents from Boeringer-Mannheim GmbH (Mannheim, Germany) using a Hitachi 917 automatic analyser (Hitachi, Tokyo, Japan).

GLP-1 concentrations in plasma were measured by radioimmunoassay after the extraction of plasma with $70 \%$ ethanol (v/v, final concentration). C-terminal GLP-1 immunoreactivity, comprising both intact, surviving GLP1 (7-36)amide and the primary metabolite, and therefore reflecting the total amount of rGLP-1 administered, was determined using antiserum 89390 which has an absolute requirement for the intact amidated C-terminus of GLP-1 (7-36)amide and cross-reacts less than $0.01 \%$ with C-terminally truncated fragments and $89 \%$ with GLP-1 (9-36)amide (Ørskov et al. 1994). Sensitivity for the assay is below $5 \mathrm{pmol} / \mathrm{l}$ and the $\mathrm{CV}$ is below $10 \%$.

The subjects then left the clinic for further ambulatory treatment at home and returned on day 5 for visit 2 .

\section{Visits 2, 3, 4, 5, 6, 7, and 8}

Visits 2 to 8 were identical to visit 1 with the difference that the administration route (CSI or PSI) or drug (rGLP1 or saline) was changed in a randomised manner. Subjects were instructed to lead their 'normal' life during the study weeks (Fig. 1).

\section{Statistical analysis}

All data were analysed according to the intention to treat (ITT) ( $n$ 19). A per protocol analysis was made for the change in weight for the subjects who completed the study (n 15) (Tukey-Kramer HSD test correcting for multiple comparisons). Data are presented as means and standard errors of the mean as appropriate.

The results were tested for normality of distribution. The two-tailed Student's $t$ test was carried out in normally distributed samples and the Mann-Whitney U test was performed where the data were not normally distributed. All statistical tests used a significance level of $P<0.05$. Within-treatment group analysis was conducted using the $t$ test in an ANOVA setting. Between-treatment group analysis was conducted using a two-way ANOVA model. A two-way repeated-measures ANOVA model was used to compare the result profiles over time. Average blood glucose, insulin, and paracetamol concentrations were calculated as areas under the curve using the trapezoidal rule. All clinical measurements were analysed using a mixed-model ANOVA. The model included fixed effects 
for sequence, treatment and period and a random effect for patients. The mean square error from the ANOVA and $t$ distribution were used in these calculations. A two-way repeated-measures ANOVA model was used to compare the result profiles over time for the EARS VAS.

For the statistical evaluation of gastric emptying with rGLP-1 or saline, either administered as PSI or as a CSI, we used a two-way ANOVA and $t$ tests with Bonferroni post hoc test adjustment.

\section{Results}

Weight

The ITT analysis could not demonstrate any change in weight before and after the $5 \mathrm{~d}$ treatment period. However, per protocol analysis demonstrated that BMI decreased during PSI rGLP-1 treatment over the $5 \mathrm{~d}$ period by 0.18 (SEM 0.08$) \mathrm{kg} / \mathrm{m}^{2}(0.55$ (SEM 0.20$\left.) \mathrm{kg}\right)(P<0 \cdot 05)$. In contrast, BMI $\left(\mathrm{kg} / \mathrm{m}^{2}\right)$ increased slightly during the placebo PSI, as well as CSI treatments with the placebo and rGLP-1 by 0.15 (SEM 0.07) $(P<0.05), 0.17$ (SEM 0.09) $(P<0.05)$ and 0.12 (SEM 0.05$)(P<0.05)$, respectively. There was a significant difference in weight change between PSI rGLP-1 and the other three experimental conditions after correcting for multiple comparisons.

A linear regression analysis between change in weight and change in amount of food eaten during the test meal on day 1 and day 5 with the placebo and rGLP-1 PSI treatment showed a positive correlation $\left(R^{2} 0.35 ; P=0.02\right)$ with decreased food intake along with decreased weight.

\section{Vital functions}

Systolic and diastolic blood pressure in the placebo experiments was not different from the values during rGLP-1 treatment. No acute or chronic haemodynamic effects were observed. No pulse reaction was noticed in any of the experiments. No effects on respiratory functions were noticed.

\section{Food intake}

There were no significant differences between the effects of rGLP-1 administered as PSI or CSI compared with saline on the amount of food eaten. However, there was a trend towards a reduction in food intake seen on day 5 with PSI treatment ( -62.5 (SEM 6.2) g $v$. saline; $P=0.07$ ).

Taking CSI and PSI treatments together to analyse the effect of rGLP-1 treatment on food intake there was no difference during the placebo $(392.3$ (SEM 42.0) g) and during rGLP-1 treatment (362.9 (SEM 41.4) g) on day 1. On day 5 the effect of rGLP-1 was more pronounced and intake of the test meal was significantly reduced from 379.7 (SEM 38.5) $\mathrm{g}$ with the placebo to 323.6 (SEM 39.9) $\mathrm{g}$ with rGLP-1 $(P=0.02)$.

\section{Visual analogue scale ratings of hunger, satiety, thirst and nausea}

Hunger. There were no significant differences between the effects of rGLP-1 administered as PSI or as CSI compared with saline on hunger ratings $300 \mathrm{~min}$ after the meal.
Taking CSI and PSI treatments together to analyse the effect of rGLP-1 treatment on hunger ratings, the ITT analysis on day 1 showed a significant suppression of VAS ratings for hunger before the meal and at $60 \mathrm{~min}$ from 55.0 (SEM 7.0) to 5.8 (SEM 3.4) $\mathrm{mm}$ in the placebo and from 49.8 (SEM 6.0) to $10 \cdot 3$ (SEM 4.2) $\mathrm{mm}$ in rGLP-1 experiments $(P=0.01)$. After the meal, at $300 \mathrm{~min}$, the hunger ratings were similar; 43.0 (SEM 5.9) $\mathrm{mm}$ in the placebo v. $37 \cdot 3$ (SEM 4.6) $\mathrm{mm}$ in rGLP-1 (NS) experiments. Correspondingly, the VAS values on day 5 showed a suppression of hunger ratings from 60 (SEM 5.1) to 7.5 (SEM 3.8 ) $\mathrm{mm}$ in the placebo and from 54.5 (SEM 5.9) to 9.5 (SEM 3.5$) \mathrm{mm}$ in the rGLP-1-treated subjects before and $60 \mathrm{~min}$ after the meal $(P=0 \cdot 03)$. At $300 \mathrm{~min}$ the values were 44.5 (SEM 5.9) v. 49.0 (SEM 5.8) $\mathrm{mm}$ for the placebo and rGLP-1 treatment, respectively (NS).

Satiety. There were no significant differences between the effects of rGLP-1 administered as a CSI compared with saline on satiety ratings $300 \mathrm{~min}$ after the meal. In contrast, on day 1 satiety ratings were 7.2 (SEM 0.9$) \mathrm{mm}(P=0.03)$ higher during the PSI treatment with rGLP-1 compared with saline. No significant differences were found on day 5 during PSI treatment.

Taking CSI and PSI treatments together to analyse the effect of rGLP-1 treatment on satiety, the ITT analysis of VAS ratings for satiety (fullness) showed a similar pattern as hunger with increased values between before the meal and $60 \mathrm{~min}$ after the meal during saline (34.3 (SEM 5.0) and 77.3 (SEM 4.8) $\mathrm{mm}$, respectively; $P<0.05)$ and rGLP-1 administration (37.8 (SEM 5.2) and 77.0 (SEM 4.2) $\mathrm{mm}$, respectively; $P<0.05)$. An increase in satiety was only observed on day 1 with rGLP-1 treatment compared with saline (5.6 (SEM 0.7) $\mathrm{mm} v$. saline; $P=0.03$ ).

Thirst. There were no significant differences in the ratings of thirst with rGLP-1 treatment or the placebo, administered by either route at any point after the meal.

Nausea. There were no differences in feelings of nausea during treatment with rGLP-1 compared with saline. Feelings of nausea that were not related to the test meal were recorded as an adverse event.

\section{Visual analogue scale at home}

No differences could be observed during at-home recordings of feelings of hunger, satiety, thirst and nausea between the rGLP-1 and placebo groups.

\section{Gastric emptying}

Calculations of T50 resulted in a significantly prolonged T50 with rGLP-1 compared with the placebo. The T50 increased from 47.0 (SEM 2.3) min with the placebo to 67.9 (SEM 2.6) min with rGLP-1 administered as PSI on day $1(P<0 \cdot 001)$, and correspondingly from $44 \cdot 1$ (SEM 2.2) min with the placebo to 69.4 (SEM 3.9) $\mathrm{min}$ on day $5(P<0.001)$. When rGLP-1 was administered as a CSI, the T50 was prolonged on day 1 from 46.9 (SEM 2.3) min with the placebo to 54.6 (SEM 3.3) min with rGLP-1 treatment $(P<0.05)$, but not on day 5 (correspondingly 44.4 (SEM 1.9) v. 46.0 (SEM 2.1) min; NS) (Fig. 2). 

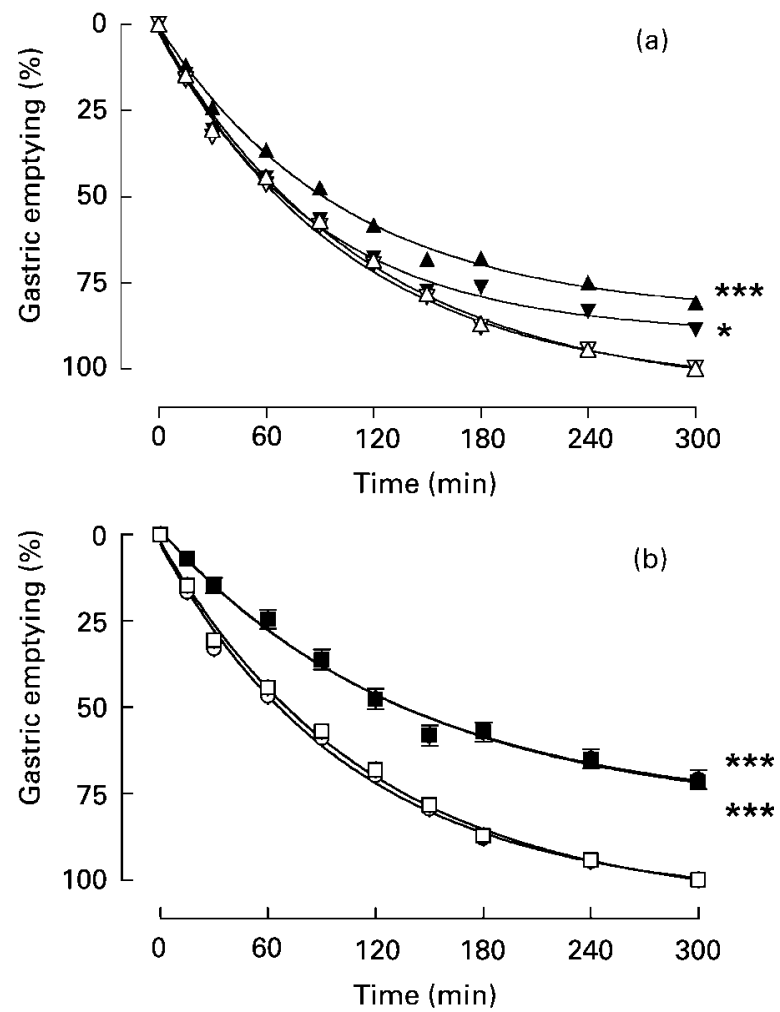

Fig. 2. Gastric emptying time as measured by the paracetamol technique in eighteen obese subjects. They were treated with a continuous subcutaneous infusion (a) of saline (placebo) or recombinant glucagon-like peptide-1 (rGLP-1) for $5 \mathrm{~d}((\Delta)$, placebo day 1 $(\nabla)$, placebo day $5 ;(\boldsymbol{\Lambda})$, rGLP-1 day $1 ;(\mathbf{\nabla})$, rGLP-1 day 5$)$ or subcutaneous prandial injections (b) of saline or GLP-1 for $5 \mathrm{~d}((\square)$, placebo day $1 ;(\bigcirc)$, placebo day 5 ; $(\mathbf{\square})$, rGLP-1 day 1 ; $(\bigcirc)$, rGLP-1 day 5). Values are means, with standard errors of the mean represented by vertical bars. ${ }^{*} P<0.05,{ }^{\star \star \star} P<0.001$; both $v$. placebo.

\section{Plasma glucagon-like peptide-1 concentrations}

In the PSI groups, the basal plasma level in the placebo group was 15.0 (SEM 1.2) $\mathrm{pmol} / \mathrm{l}$ with a peak of 28.9 (SEM 2.3) pmol/l occurring $30 \mathrm{~min}$ after the start of the meal. With rGLP-1 injections, plasma concentrations rose from 25.8 (SEM 2.7) to 269.4 (SEM 22.1) $\mathrm{pmol} / \mathrm{l}$ at $15 \mathrm{~min}$ after the meal and returned to the basal levels within $180 \mathrm{~min}$. In the CSI groups, a minor rise of GLP-1 was observed from basal values (measured $4 \mathrm{~h}$ after the start of the infusion pump) of 49.7 (SEM 5.9) pmol/l to a peak concentration of 88.7 (SEM 13.1) $\mathrm{pmol} / \mathrm{l}$ at $15 \mathrm{~min}$ after the meal (Fig. 3).

\section{Plasma glucose, insulin and glucagon concentrations}

Plasma glucose and glucagon concentrations were decreased and plasma insulin increased after PSI of rGLP-1. No significant alterations in plasma glucose, insulin or glucagon concentrations were seen during the CSI of rGLP-1 (Fig. 3).

\section{Adverse events}

Feelings of sickness and abdominal pain were the most frequently reported side effects. rGLP-1 treatment resulted in a significant increase only in the frequency of feeling of sickness, compared with the placebo in the PSI experiments $(P=0 \cdot 05)$. However, when all the adverse events were evaluated together, a significantly increased frequency was observed in the PSI experiments but not under CSI treatment. No effects of rGLP-1 were observed on blood pressure or heart rate (Table 1).

\section{Discussion}

The present study demonstrates that PSI of rGLP-1 during $5 \mathrm{~d}$ in obese subjects results in a weight loss of $0.5 \mathrm{~kg}$ during this time period. With a CSI of the same amount of rGLP-1, no significant weight loss occurred over a corresponding period. The reduction in weight was associated with a significant slowing of gastric emptying and a trend towards a reduced food intake, but no change of feelings of hunger and satiety. The PSI treatment was generally well tolerated by the subjects and resulted in an improved metabolic profile with balanced postprandial glucose and insulin concentrations.

Other studies have shown that SC administration of GLP-1 for up to 6 weeks reduces weight (Zander et al. 2002), yet the present study is the first to demonstrate this effect with PSI in direct association with meals. Previous studies over short time periods $(4-8 \mathrm{~h})$ have demonstrated that GLP-1 inhibits food intake and reduces feelings of hunger, as verified by a recent meta-analysis (Verdich et al. 2001). In the present study we did not find any effect of either PSI or CSI of rGLP-1 on feelings of hunger, but a trend towards a reduction in food intake during PSI of rGLP-1. One reason for this may be that since the present study was designed as an ambulatory at-home study, VAS estimations were chosen to be made at $60 \mathrm{~min}$ intervals. Hence, the first hunger rating was measured $60 \mathrm{~min}$ after the meal in the present study compared with immediately after the cessation of food intake in previous studies on obese subjects (Näslund et al. 1999a). Due to this choice of assessment we found fewer variations in the hunger ratings, and trough values were most probably not recorded.

Similarly, there is a question whether the dose of rGLP-1 administered during the CSI experiments was high enough to result in effects on eating behaviour (Zander et al. 2002). In the present study, the mean plasma GLP-1 concentration before the meal in the CSI group was $65 \mathrm{pmol} / \mathrm{l}$. This may not be sufficient to suppress food intake, as previous studies suggest that concentrations of about $100 \mathrm{pmol} / \mathrm{l}$ before food intake are needed in order to achieve a reduction in food intake (Näslund et al. 1999a). Also, a newly published meta-analysis showed a clear dose-response relationship between the reduction of food intake and plasma GLP-1 concentrations (Verdich et al. 2001). Furthermore, as suggested in this meta-analysis, obese subjects may have a lower sensitivity to GLP-1 and may require higher doses in order to obtain effects on satiety.

The results with regards to gastric emptying are in accordance with previously published papers on the effect of GLP-1 on gastric emptying (Nauck et al. 1997; Näslund et al. 1999b). During PSI the gastric emptying 

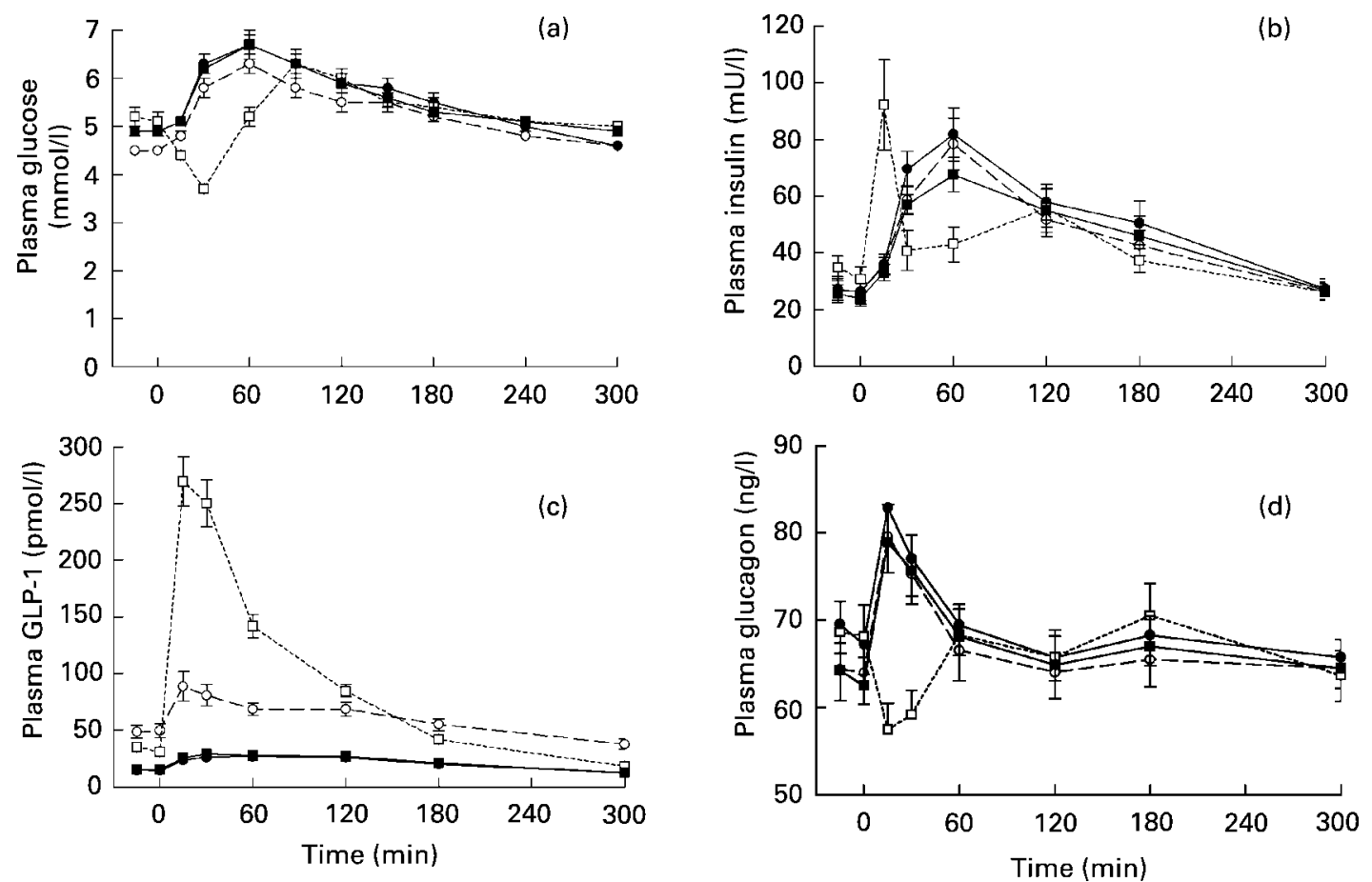

Fig. 3. Plasma glucose (a), insulin (b), C-terminal glucagon-like peptide-1 (GLP-1; (c)) and glucagon (d) concentrations in eighteen obese subjects receiving either saline or recombinant GLP-1 (rGLP-1) as a continuous subcutaneous infusion (CSI) or prandial subcutaneous injections (PSI) for $5 \mathrm{~d}$. (๑), Placebo PSI; $(\bullet)$, placebo CSI; (口), rGLP-1 PSI; (०), rGLP-1 CSI. Values are means, with standard errors of the mean represented by vertical bars.

was equally inhibited on day 1 and day 5. Yet, during CSI no significant inhibition of gastric emptying was found on day 5. However, on this day, plasma GLP-1 concentrations were also lower.

A delay in gastric emptying may be one mechanism for GLP-1 to exert its effects on food intake and the observed weight loss. Distension of the stomach with increasing feelings of fullness subsequently leading to prolonged postprandial satiety and reduced food intake may be one potential mechanism for the GLP-1 action on weight loss (Flint et al. 1998). In the present study, during PSI of rGLP-1, increased plasma concentrations were elevated already at the start of the meal. This would favour the view that high GLP-1 levels already at the onset of food intake should reliably decrease gastric emptying and increase the prandial satiety period (Gutniak et al. 2001). As shown in another study from our group, GLP-1 has to be timely administered at the onset of a meal to cause the inhibition of gastric emptying (Gutniak et al. 2001). Another mechanism by which GLP-1 may influence food intake is directly in the central nervous system. Ørskov et al. (1996) identified peripherally injected $\left[{ }^{125} \mathrm{I}\right] \mathrm{GLP}-1$ in the subfornical organ and periphery

Table 1. Frequency of adverse events in prandial injection (PSI) and continuous infusion (CSI) of placebo or recombinant glucagon-like peptide-1 (rGLP-1)*

\begin{tabular}{|c|c|c|c|c|c|c|}
\hline \multirow[b]{2}{*}{ Adverse event } & \multicolumn{2}{|c|}{ PSI } & \multicolumn{2}{|c|}{ CSI } & \multicolumn{2}{|c|}{$P$ valuet } \\
\hline & Placebo & rGLP-1 & Placebo & rGLP-1 & PSI & CSI \\
\hline Abdominal pain & 1 & 4 & 2 & 3 & NS & NS \\
\hline Feeling of sickness & 2 & 8 & 2 & 1 & 0.05 & NS \\
\hline Nausea & 4 & 3 & 1 & 6 & NS & NS \\
\hline Dizziness & 0 & 1 & 0 & 2 & NS & NS \\
\hline Headache & 0 & 1 & 0 & 1 & NS & NS \\
\hline Respiratory infection & 0 & 0 & 2 & 0 & NS & NS \\
\hline Sweating & 0 & 0 & 0 & 1 & NS & NS \\
\hline Polyuria & 2 & 1 & 0 & 0 & NS & NS \\
\hline Thirst & 0 & 0 & 1 & 0 & NS & NS \\
\hline Mouth dryness & 0 & 0 & 2 & 0 & NS & NS \\
\hline Taste alteration & 0 & 1 & 0 & 0 & NS & NS \\
\hline Visual defect & 0 & 1 & 0 & 0 & NS & NS \\
\hline Complication to CSI or PSI & 0 & 1 & 2 & 2 & NS & NS \\
\hline Total events & 9 & 21 & 12 & $1 \overline{6}$ & 0.02 & NS \\
\hline Total subjects & 7 & 19 & 11 & 12 & 0.01 & NS \\
\hline
\end{tabular}

${ }^{*}$ For details of procedures, see p. 440

†Significance between placebo and rGLP-1. 
of the area postrema. These areas are reported to project to nuclei in the central nervous system involved in the regulation of food intake (Shapiro \& Miselis, 1985). Furthermore, damage to the nucleus arcuatus and circumventricular organ by neonatal monosodium glutamate treatment has been shown to diminish the inhibitory effect of GLP-1 on food intake (Tang-Christensen et al. 1998). Thus, both a peripheral effect mediated via the vagus nerve in concert with a central effect may contribute to the reduction in body weight observed in the present study with PSI rGLP-1 administration.

On day 5 during CSI, rGLP-1 infusion plasma concentrations were lower than those on day 1 . The reasons for this are not clear, but indicate an increased plasma clearance, either due to an increased metabolic rate, renal excretion or increased volume of distribution of GLP-1. The underlying pharmacokinetic mechanisms for such observations are yet to be revealed. These findings may also account for the lack of effect by the CSI of rGLP-1 on body weight and food intake. This also pinpoints the problem of delivering natural GLP-1 to human subjects. GLP-1 has been shown to be very stable in the absence of plasma (Mojsov et al. 1987). Yet, in plasma or SC tissue the half-life is very short. After about 2 min most of the peptide is cleaved by the enzyme dipeptidyl-peptidase IV (Mentlein et al. 1993). It is possible that the dipeptidyl-peptidase IV activity was enhanced in the area of SC tissue where the needle for the CSI of rGLP-1 was placed, thus resulting in decreasing plasma concentrations over the $5 \mathrm{~d}$ period. This also demonstrates the problems of peptide delivery in the clinical setting. Clearly the results of rGLP-1 on food intake in the present study were dependent on the plasma concentration of GLP-1 achieved. With the present study design a sufficiently high plasma concentration was only achieved with the PSI mode of delivery. PSI of rGLP-1 resulted in a slight weight loss and improvement of metabolic parameters, yet this was also associated with an increase in adverse events which may be the result of the high peak of plasma GLP-1 seen during PSI. There is a need for a mode of delivery that can achieve sufficiently high plasma concentrations to influence food intake and metabolic parameters without the sharply increased plasma GLP-1 levels seen during the PSI administration seen in the present study. Studies employing stable GLP-1 analogues are underway (Larsen et al. 2001) and similarly the natural GLP-1 analogue, exendin-4, has been shown to reduce energy intake in human volunteers (Edwards et al. 2001).

To conclude, a $5 \mathrm{~d}$ treatment of rGLP-1 at high doses by PSI promptly slowed gastric emptying as one possible mechanism of action of increased satiety, decreased hunger and, hence, reduced food intake with an ensuing weight loss. This finding is in contrast to the CSI of the same total dose of rGLP-1, which does not reach the plasma levels needed to achieve the inhibition of gastric emptying and, hence, has no effects on satiety and hunger, as well as food intake and body weight. The prandial injections were not associated with any severe adverse events. Thus, it is concluded that slowed gastric emptying presents an avenue for how GLP-1 reduces food intake and causes weight loss.

\section{Acknowledgements}

The present study was supported by grants from the Swedish Research Council, the Danish Medical Research Council, the Swedish Society of Medicine, and by funds of the Karolinska Institutet, the Professor Nanna Svartz Fund, the Tore Nilsson Fund, the Thuring Fund, the Grönberg Fund, the Ruth and Richard Juhlin Fund, Jeanssons Foundation, and the Bengt Ihre Foundation. We would like to dedicate this paper to Mark Gutniak, who sadly passed away recently, for his contributions in the field of GLP-1 and his friendship.

\section{References}

Barkeling B, Rössner S \& Björvell H (1990) Effects of high-protein meal (meat) and a high-carbohydrate meal (vegetarian) on satiety measured by automated computerized monitoring on subsequent food intake. Int J Obes Relat Metab Disord 14, $743-751$.

Edwards CM, Stanley SA, Davis R, Brynes AE, Frost GS, Seal LJ, Ghatei MA \& Bloom SR (2001) Exendin-4 reduces fasting and postprandial glucose and decreases energy intake in healthy volunteers. Am J Physiol 281, E155-E166.

Flint A, Raben A, Astrup A \& Holst JJ (1998) Glucagon-like peptide 1 promotes satiety and suppresses energy intake in humans. J Clin Invest 101, 515-520.

Grybäck P, Hermansson G, Lyrenäs E, Beckman K-W, Jacobsson H \& Hellström PM (2000) Nationwide standardisation and evaluation of scintigraphic gastric emptying: reference values and comparison between subgroups in a multicentre trial. Eur J Nucl Med 27, 647-655.

Gutniak MK, Linde B, Holst JJ \& Efendic S (1994) Subcutaneous injection of the incretin hormone glucagon-like peptide 1 abolishes postprandial glycemia in NIDDM. Diabetes Care $\mathbf{9}$, $1039-1044$.

Gutniak MK, Ørskov C, Holst JJ, Ahrén B \& Efendic S (1992) Antidiabetogenic effect of glucagon-like peptide-1 (7-36) amide in normal subjects and patients with diabetes mellitus. $N$ Engl J Med 326, 1316-1322.

Gutniak MK, Svartberg J, Hellström PM, Holst JJ, Adner N \& Ahrén B (2001) Antidiabetogenic action of glucagon-like peptide-1 related to administration relative to meal intake in subjects with type 2 diabetes. $J$ Intern Med 250, 81-87.

Gutzwiller JP, Drewe J, Göke B, Schmidt H, Rohrer B, Lareida J \& Beglinger C (1999a) Glucagon-like peptide-1 promotes satiety and reduces food intake in patients with diabetes mellitus type 2. Am J Physiol 276, R1541-R1544.

Gutzwiller JP, Göke B, Drewe J, Hildebrand P, Ketterer S, Handschin D, Winterhalder R, Conen D \& Beglinger C (1999b) Glucagon-like peptide-1: a potent regulator of food intake in humans. Gut 44, 81-86.

Kreymann B, Ghatei MA, Burnett P, Williams G, Kanse S, Diani AR \& Bloom SR (1989) Characterization of glucagon-like peptide 1 (7-36)amide in the hypothalamus. Brain Res 502, $325-331$.

Kreymann B, Williams G, Ghatei MA \& Bloom SR (1987) Glucagon-like peptide-1 7-36: a physiological incretin in man. Lancet ii, 1300-1303.

Larsen PJ, Tang-Christensen M, Holst JJ \& Ørskov C (1997) Distribution of glucagon-like peptide-1 (GLP-1) and other preproglucagon derived peptides in the rat hypothalamus and brain stem. Neuroscience 77, 257-270.

Larsen PJ, Tang-Christensen M \& Knudsen LB (2001) Systemic administration of the long-acting GLP-1 analogue, NN2211, 
induces lasting and reversible loss of body obesity. Diabetologia 43, Suppl. 1, A144.

Mentlein R, Gallwitz B \& Schmidt WE (1993) Dipeptidyl-peptidase IV hydrolyses gastric inhibitory polypeptide, glucagonlike peptide-1(7-36)amide, peptide histidine methionine and is responsible for their degradation in human serum. Eur J Biochem 214, 829-835.

Mojsov S, Weir GC \& Habener JF (1987) Insulinotropin: glucagon-like peptide I (7-36) co-coded in the glucagon gene is a potent stimulator of insulin release in the perfused rat pancreas. $J$ Clin Invest 79, 616-619.

Näslund E, Barkeling B, King N, Gutniak MK, Blundell JE, Holst JJ \& Hellström PM (1999a) Energy intake and appetite are suppressed by glucagon-like peptide-1 (GLP-1) in obese men. Int $J$ Obes Relat Metab Disord 23, 304-311.

Näslund E, Bogefors J, Skogar S, Grybäck P, Jacobsson H, Holst JJ \& Hellström PM (1999b) GLP-1 slows solid gastric emptying and inhibits insulin, glucagon, and PYY release in humans. Am J Physiol 277, R910-R916.

Näslund E, Grybäck P, Jacobsson H \& Hellström PM (2000) Gastric emptying: a comparison of scintigraphic, marker dilution and paracetamol absorption assessment techniques. Scand $J$ Gastroenterol 35, 375-379.

Näslund E, Gutniak MK, Skogar S, Rössner S \& Hellström PM (1998) Glucagon-like peptide 1 increases the period of postprandial satiety and slows gastric emptying in obese men. Am $J$ Clin Nutr 68, 525-530.

Nauck MA, Heimesaat MM, Ørskov C, Holst JJ, Ebert R \& Creuzfeldt W (1993a) Preserved incretin activity of glucagon-like peptide 1(7-36amide) but not synthetic human gastric inhibitory polypeptide in patients with type-2 diabetes mellitus. $J$ Clin Invest 91, 301-307.

Nauck MA, Kleine N, Ørskov C, Holst JJ, Willms B \& Creuzfeldt W (1993b) Normalization of fasting hyperglycemia by exogenous glucagon-like peptide 1 (7-36amide) in type 2 (non-insulindependent) diabetic patients. Diabetologia 36, 741-744.

Nauck MA, Niedereichholz U, Ettler R, Holst JJ, Ørskov C \& Ritzel R \& Schmiegel W (1997) Glucagon-like peptide 1 inhibition of gastric emptying outweighs its insulinotropic effects in healthy humans. Am J Physiol 273, E981-E988.

Nauck MA, Wollschläger D, Werner J, Holst JJ, Ørskov C,
Creuzfeldt W \& Willms B (1996) Effects of subcutaneous glucagon-like peptide 1(GLP-1[7-36]amide) in patients with NIDDM. Diabetologia 39, 1546-1553.

Ørskov C, Poulsen SS, Møller M \& Holst JJ (1996) Glucagon-like peptide I receptors in the subfornical organ and area postrema are accessible to circulating glucagon-like peptide I. Diabetes 45, 832-835.

Ørskov C, Rabehøj L, Wettergren A, Kofod H \& Holst JJ (1994) Tissue and plasma concentrations of amidated and glycineextended glucagon-like peptide I in humans. Diabetes 43, $535-539$.

Ritzel R, Ørskov C, Holst JJ \& Nauck MA (1995) Pharmacokinetic, insulinotropic, and glucagono-static properties of GLP-1 (7-36 amide) after subcutaneous injection in healthy volunteers. Dose-response-relationships. Diabetologia 38, $720-725$.

Shapiro RE \& Miselis RR (1985) The central neural connections of the area postrema in the rat. J Comp Neurol 234, 344-364.

Tang-Christensen M, Vrang N \& Larsen PJ (1998) Glucagon-like peptide 1(7-36)amide's central inhibition of feeding and peripheral inhibition of drinking are abolished by neonatal monosodium glutamate treatment. Diabetes 47, 530-537.

Todd JF, Wilding JPH, Edwards CMB, Kahn FA, Ghatei MA \& Bloom SR (1997) Glucagon-like peptide-1 (GLP-1): a trial of treatment in non-insulin-dependent diabetes mellitus. Eur $J$ Clin Invest 27, 533-536.

Toft-Nielsen M-B, Madsbad S \& Holst JJ (1999) Continuous subcutaneous infusion of glucagon-like peptide-1 lowers plasma glucose and reduces appetite in type 2 diabetic patients. Diabetes Care 22, 1134-1137.

Turton MD, O'Shea D, Gunn I, et al. (1996) A role for glucagonlike peptide-1 in the central regulation of feeding. Nature $\mathbf{3 7 9}$, 69-72.

Verdich C, Flint A, Gutzwiller JP, et al. (2001) A meta-analysis of the effect of glucagon-like peptide-1 (7-36)amide on ad libitum food intake in humans. J Clin Endocrinol Metabol 86, 4382-4389.

Zander M, Madsbad S, Madsen JL \& Holst JJ (2002) Effect of 6-week course of glucagon-like peptide-1 on glycemic control, insulin sensitivity, and beta-cell function in type 2 diabetes: a parallel-group study. Lancet 359, 824-830. 